\title{
Metabolic Post-feeding Changes in Fat Body and Hemolymph of Dipetalogaster maximus (Hemiptera:Reduviidae)
}

\author{
Lilián E Canavoso, Edilberto R Rubiolo*/+
}

Departamento de Bioquímica Clínica, Facultad de Ciencias Químicas, UNC, Agencia Postal 4, CC 61, CP 5000, Córdoba, Argentina *Servicio Nacional de Chagas, Ministerio de Salud y Acción Social, Córdoba, Argentina

Lipids and glycogen in fat body as well as the modifications in the wet weight of this organ were evaluated in an unfed insect, Dipetalogaster maximus, on day 5 after adult ecdysis (time 0 ) and during a 30-day period after ingestion of blood meal. Total lipids, high density lipophorin (HDLp), carbohydrates, total proteins and uric acid were determined in the hemolymph during the same period.

Fat body wet weight was maximum on day 10 post-feeding and represented on day 30 only $42 \%$ of the maximum weight. Lipids stored in the fat body increased up to day 15 reaching $24 \%$ of the total weight of tissue. Glycogen was maximum on day 20, representing approximately $3 \%$ of the fat body weight. HDLp represented at all times between 17-24\% of the total proteins, whose levels ranged between 35 and $47 \mathrm{mg} / \mathrm{ml}$. Uric acid showed at 20, 25 and 30 days similar levels and significantly higher than the ones shown at days 10 and 15. Hemolymphatic lipids fluctuated during starvation between $3-4.4 \mathrm{mg} / \mathrm{ml}$ and carbohydrates showed a maximum on day 15 after a blood meal, decreasing up to $0.26 \mathrm{mg} / \mathrm{ml}$ on day 25 .

The above results suggest that during physiological events such as starvation, the availability of nutrients is affected, involving principally the fat body reserves.

Key words: carbohydrates - Dipetalogaster maximus - fat body - hemolymph - lipids - lipophorin - proteins

The study of hemolymph components as well as of fat body deposits involved in essential metabolic processes related to supply of energy in insects for activities such as flight, reproduction, embryogenesis and metamorphosis provide important information about physiology of members of the same or different species (Wigglesworth 1972, Wyatt \& Pan 1978).

Most animal species are able to overcome fasting periods and each species fits its metabolism into the particular situation of living, mobilizing its reserves when food is not available. However, among insects belonging to the same family, there is a remarkable difference in the possibilities of getting a food source resulting in distinct metabolic adaptation against fasting situations (Ziegler 1991).

Several factors such as diet, temperature and disease influence the insect hemolymph composition of a species (Mullins 1985). The fat body, a tissue with multiple metabolic functions, performs

This work was supported by grants from SECyTUniversidad Nacional de Córdoba and CONICOR.

+Corresponding author. Fax: +54-51-334174

Received 21 July 1997

Accepted 15 January 1998 important biosynthetic activity during the whole life of the insect and serves for nutrient storage (Keeley 1985).

In reduviid bugs, hemimetabolous and obligately hematophagous insects, feeding and deposits in the fat body of metabolic reserves are important elements to cover their needs in the different stages as well as for their survival as adults (Friend $\&$ Smith 1985). Nowadays, the information in fasted reduviids about biochemical changes in fat body as well as metabolic compounds related to supply of energy is rather scarce. This is an important aspect since the low weight, low weight/ length ratio of the insect (Schofield 1980, Lehane \& Schofield 1980, Schofield et al. 1992), a poor nutritional status (starvation) (Sjogren \& Ryckman 1966) and the need of a previous fasting period (Gringorten \& Friend 1979, Ward et al. 1982) have been pointed out in different species of reduviid bugs as factors stimulating flight. More recently, we demonstrated in vitro that three species of triatomine bugs have the biochemical constituents for generating partial transformation of high density lipophorin (HDLp) into low density ones (LDLp), employing fat bodies with more than 20 days of starvation (Canavoso \& Rubiolo 1994, 1995). This suggests the importance of the metabolic reserve levels available in the fat body dur- 
ing flight. This activity is an important mechanism of active dispersion by the vectors of Trypanosoma cruzi, responsible for American trypanosomiasis (WHO 1991).

In the present study, we report the post-feeding modifications on fat body and hemolymph in a member of the Hemiptera order, Reduviidae family, the Dipetalogaster maximus. Adult insects fed 5 days after final ecdysis were submitted to different periods of starvation for 30 days. In fat body were analyzed the variations of glycogen, total lipids and the organ wet weight and in the hemolymph, the total lipids, HDLp, total proteins, uric acid and carbohydrates.

\section{MATERIALS AND METHODS}

Chemicals - All chemical reagents were of analytical grade. Doubly redistilled water was used throughout the experiments.

Insects - Colonies of triatomine bugs D. maximus were reared and kept in the insectary, fed fortnightly on hens' blood. For the experiences, male grown-up insects were fed at day 5 after final ecdysis and separated in groups of 10-15 insects with similar weights. These groups were starved for $10,15,20,25$ and 30 days post-feeding and maintained at $28^{\circ} \mathrm{C} \pm 1^{\circ} \mathrm{C}, 60-70 \%$ humidity and 8:16 hr light:dark photoperiod as previously reported (Canavoso \& Rubiolo 1993).

Groups of 10-15 insects in similar conditions and without meal were used at day 5 after final ecdysis in order to determine lipids and glycogen in fat body and the wet weight of the organ (time 0 ).

Hemolymph collection - After 10, 15, 20, 25 and 30 days post-feeding, the hemolymph from the groups of insects was collected by centrifugation in the presence of $10 \mathrm{mM} \mathrm{Na}{ }_{2}$ EDTA and mixture of protease inhibitors (Canavoso \& Rubiolo 1993). The hemolymph samples were centrifuged at $10,000 \mathrm{~g}$ for $10 \mathrm{~min}$ at $4^{\circ} \mathrm{C}$ to remove hemocytes and stored at $-70^{\circ} \mathrm{C}$ until assays were performed. For the carbohydrates determination, the hemolymph was collected only with $\mathrm{Na}_{2}$ EDTA and immediately used.

Chemical determinations in hemolymph - Protein concentrations have been determined by Bradford (1976), using albumin bovine as standard whereas uric acid was determined by enzymatic methods, employing a commercial kit (Uricostat, Wiener Lab., Argentina). Total lipid determinations were performed according to Frings and Dunn (1970) and carbohydrates, according to Scott and Melvin (1953).

\section{Determination of lipophorin HDLp}

Lipophorin standard - A standard curve for measurement of HDLp by ELISA was carried out employing HDLp from D. maximus, isolated from hemolymph by $\mathrm{KBr}$ density gradient ultracentrifugation and dialysed overnight against phosphate buffered saline (PBS) at pH 7.4 (Canavoso \& Rubiolo 1995). The concentration of lipophorin standard was quantified by Bradford (1976).

ELISA assays - An indirect ELISA was performed in order to determine lipophorin titer (Voller et al. 1976). Microtiter plates (Labsystem) were loaded with $200 \mathrm{ml} /$ well of the lipophorin standard (10-16 ng) or hemolymph from different times post-feeding diluted $(1: 300,000$ to $1: 1.000,000)$ with buffer $(15 \mathrm{mM}$ sodium carbonate, $35 \mathrm{mM}$ sodium bicarbonate, $\mathrm{pH}$ 9.6) and incubated for 120 $\min$ at $37^{\circ} \mathrm{C}$. Then, the microplates were washed five times with phosphate-buffered saline with Tween 20 (PBS-Tween) $(8.2 \mathrm{mM}$ sodium phosphate, $1.5 \mathrm{mM}$ potassium phosphate, $150 \mathrm{mM}$ sodium chloride, $2.7 \mathrm{mM}$ potassium chloride, $0.05 \%$ Tween 20, pH 7.4).

Serum anti-lipophorin HDLp from adults of $D$. maximus, obtained in rabbits as described previously (Canavoso \& Rubiolo 1995), was diluted in PBS-Tween $(1: 10.000)$ containing $0.1 \%$ bovine serum albumin and loaded into each well incubating for $60 \mathrm{~min}$ at $37^{\circ} \mathrm{C}$. Plates were washed and loaded with anti-rabbit inmunoglobulin conjugated to horseradish peroxidase (Sigma) in PBS-Tween and incubated for $30 \mathrm{~min}$ at $37^{\circ} \mathrm{C}$. Then, the plates were washed again and developed at $37^{\circ} \mathrm{C}$ for 30 min with $o$-phenylenediamine in substrate buffer ( $81.5 \mathrm{mM}$ sodium phosphate, $33.3 \mathrm{mM}$ citric acid; $0.08 \%$ hydrogen peroxide, $\mathrm{pH} 5.0$ ) and read at 490 nm.

Determination of fat body wet weight - At time 0 (unfed insects, 5 days after final ecdysis) and after 10, 15, 20, 25 and 30 days post-feeding, fat bodies were carefully dissected, washed, dried on filter paper and weighed with a $\pm 0.01 \mathrm{mg}$ precision.

Determination of lipids and glycogen in fat body - The lipids extraction was carried out according to Folch et al. (1957) and the material was taken up to constant weight in a $\mathrm{N}_{2}$ atmosphere. For determination of glycogen, the fat bodies were homogenized in a $\mathrm{KOH} 30 \%$, boiled for $30 \mathrm{~min}$ and precipitated with ethanol (Hassid \& Abraham 1957). Then, the carbohydrates were determined by the anthrone method (Scott \& Melvin 1953).

Statistical analysis - Student's $t$ tests for observations were utilized in all instances. Results are reported as a mean \pm SEM.

\section{RESULTS}

Fat body wet weight of $D$. maximus after a blood meal changed with starvation compared to unfed insects (time 0), reaching $49.32 \pm 2.07 \mathrm{mg}$ 
on day 10 and decreasing to $20.52 \pm 2.68 \mathrm{mg}$ in insects fasting for 30 days $(P<0.01$ day $30 v s$ day 10). The last value represented only $42 \%$ of the maximum wet weight reached. In the insects fasting during 25 days, the fat body wet weight was similar to that found in unfed animals (Fig. 1).

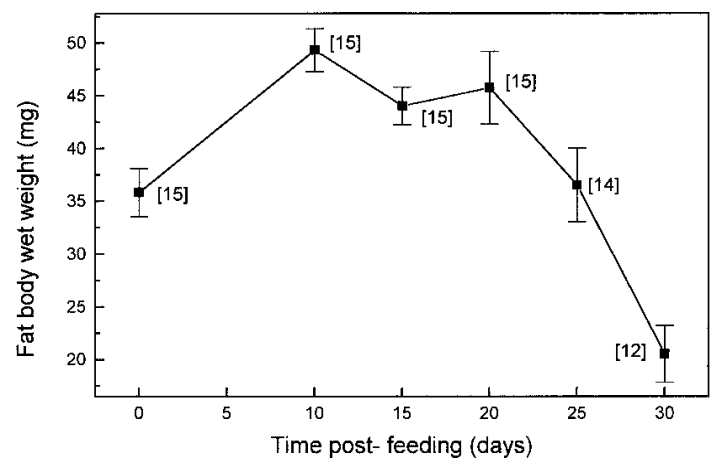

Fig. 1: fat body wet weight of Dipetalogaster maximus in unfed insects (time 0, day 5 after final ecdysis) and at different times post- feeding. Values are mean \pm SEM for the number of animals indicated in brackets, determined in duplicate.

Fig. 2 shows the variations of the total lipids in fat body as well as hemolymphatic levels of lipids and HDLp from unfed insects and at different times of post-feeding. It was observed that on day 15 , the lipids pool in the tissue was the highest and represented $24 \%$ of the organ wet weight $(10.7 \mathrm{mg}$ per fat body). At later times, the stored lipids showed a marked fall, representing on day 30 only $2.1 \mathrm{mg}$ per fat body (10\% of the organ wet weight) $(P<0.001$ day 15 vs 20,25 and 30 days). In the groups of insects recently moulted and unfed (time 0 ), the deposits of lipids were similar to those found at day 20 post-feeding although higher than values at 25 and 30 days. On the other hand, the levels of the hemolymphatic lipids fluctuated throughout the period studied, reaching values between 3 and $4.4 \mathrm{mg} / \mathrm{ml}$. The hemolymphatic HDLp levels, measured by indirect ELISA, ranged between 6.3 $\mathrm{mg} / \mathrm{ml}$ and $9.7 \mathrm{mg} / \mathrm{ml}$ at different times post-feeding.

Previous to feeding of the insects, the glycogen reserves in fat body represented only $0.78 \%$ of the tissue $(0.28 \mathrm{mg}$ per fat body). This value is 5 and 1.3 folds lower than the maximum (day 20) and the value at day 30 post-feeding respectively (Fig. 3) whereas the concentration of carbohydrates in the hemolymph underwent important changes, dropping from $0.52 \mathrm{mg} / \mathrm{ml}$ to 0.26 and $0.28 \mathrm{mg} / \mathrm{ml}$ during the two last periods analyzed.

As shown in Fig. 4, the maximum value of proteins was reached on day 20 in a similar way as lipophorin. In this hematophagous species was also determined the major product from proteins metabolism, the uric acid. A continuous increase was observed with the course of starvation, reaching the maximum level on day $30(0.16 \mathrm{mg} / \mathrm{ml})$ (Fig. 4). Another proteic metabolite such as urea remains with undetectable levels during all periods of starvation.

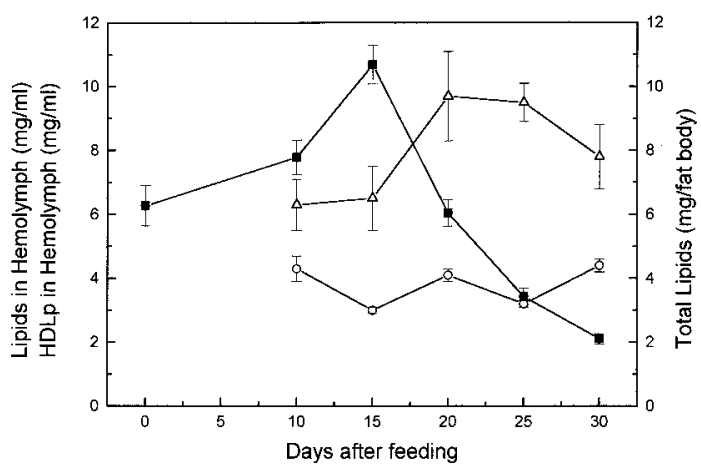

Fig. 2: variations of lipids (-O-) and HDLp (- $\triangle$-) in hemolymph and deposits of total lipids in fat body (-口-) at different times post-feeding. Values are mean \pm SEM $(n=10)$, determined in duplicate.

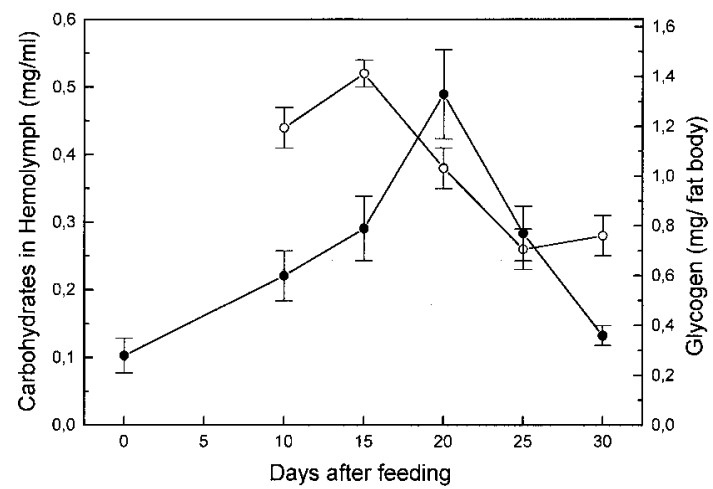

Fig. 3: variations of carbohydrates in hemolymph (-O-) and glycogen deposits in fat body (--) at different times post-feeding. Values are mean $\pm \operatorname{SEM}(n=10)$, determined in duplicate.

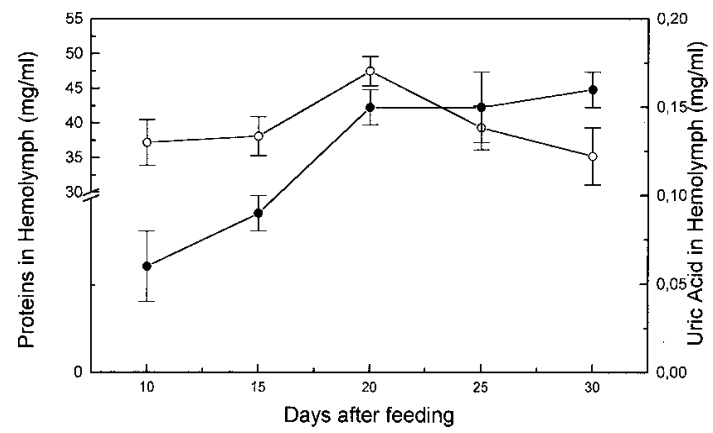

Fig. 4: concentration of total proteins (-O-) and uric acid (-๑-) in hemolymph of Dipetalogaster maximus at different times post-feeding. Values are mean \pm SEM $(n=10)$, determined in duplicate. 


\section{DISCUSSION}

Fat body in insects may be considered functionally, analogous to both vertebrate liver and adipose tissue, serving not only for the storage of reserves, but also as a general center for intermediary metabolism (Beenakkers et al. 1985). The hemolymph is the medium through which nutrients are transported from the sites of absorption directly to the sites of tissue respiration or to storage organs and, subsequently, to sites of utilization. Also, it transports waste products to excretory organs and all chemical exchanges between the organs affected (Wigglesworth 1972, Beenakkers et al. 1985).

The present work reports about biochemical modifications occurring in the fat body reserves and in the hemolymph after a blood meal in the hemipteran D. maximus. They were evaluated in fat body through glycogen, total lipids and wet weight of the organ as well as by hemolymphatic levels of carbohydrates, total lipids, HDLp, proteins and uric acid. This hemimetabolous insect, a unique species of their genera, lives among rocks and feeds principally on blood lizards and wild mammalians (Ryckman \& Ryckman 1967, Beltran \& Carcavallo 1985). Despite the blood meal results critic for reduviids metamorphosis and that the nutritional reserve after moulting has an important effect on the development and growth (Friend \& Smith 1985), their ability to survive long periods without feed is well known (Szumlewicz 1976).

Blood ingested by triatomine bugs is primarily stored in the anterior midgut where water absorption occurs quickly whereas the major digestion and absorption processes are relegated to posterior midgut (Terra \& Ferreira 1994). These events are influenced by amount of consumed blood, physiological status, sex and temperature (Catalá et al. 1992). Our results indicated that after feeding D. maximus performs its digestion process accumulating reserves continuously up to day 20 post-feeding. In this period, the maximum value of the fat body wet weight was reached at day 10 . At days 25 and 30 post-feeding, fat body wet weight showed an appreciable decrease, indicating that the mobilization process of reserves prevails over storage process, representing at day 30 less than $50 \%$ of the maximum weight (Fig. 1). However, the ratio between total weight of insect and fat body wet weight did not show significant changes through the times analyzed; the fat body being about $5 \%$ of the total weight of insect (data not shown).

Deposits of total lipids and glycogen showed similar patterns, differing at times at which they reached the maximum values (Figs 2, 3). An interesting aspect was observed in glycogen content found at day 30 , glycogen at this time being higher than the ones found in unfed insects (time $0)$. This phenomenon associated to lipidic deposits at time 0 and to nutritional reserves after ecdysis as pointed by Friend and Smith (1985) could suggest that these hematophagues employ the carbohydrates preferably at lipidic reserves, generating fuel to moulting as adult and reserving lipids for eventual flights in order to look for food. This speculation is supported by the higher energetic value of lipids compared to carbohydrates and the fact that lipids are generally the major fuel for flight used for insects (Beenakkers et al. 1985).

Unlike glycogen, the lipidic deposits decreased markedly after day 15 post-feeding up to day 25 , when they represented only $3.4 \mathrm{mg}$ per fat body (Fig. 2). They showed triacylglycerols as a predominating lipid amongst non-polar components and phosphatidylcholine and phosphatidylethanolamine as the main polar components (Canavoso et al. 1996).

Influence of starvation upon fat body weight and carbohydrates metabolism has been reported in the phytophagous hemimetabolous Carausius morosus. It was observed that glycogen content decreased after $15 \mathrm{hr}$ of starvation and virtually disappears after $24 \mathrm{hr}$ whereas fat body weight decreased during a 4-day period of starvation by about 30\% (Lohr \& Gade 1983). Influence of starvation has also been analyzed in the holometabolous Manduca sexta by Ziegler (1991). Thus, it was observed after 5 days of starving a decrease in both, the fat body dry weight and in the lipidic content while glycogen reserves were exhausted. A similar pattern was demonstrated in adult locusts (Jutsum et al. 1975). It is possible therefore that the striking differences in carbohydrate deposits before described may be attributed to different processes of digestion between these hematophagous insects and phytophagues.

On the other hand, levels of hemolymphatic carbohydrates extremely elevated or absent have been reported in insects and some arthropods (Bedford 1977). In this respect, our results obtained for $D$. maximus were lower compared to other members of the Insecta class: Periplaneta americana (Steele 1961), Locusta migratoria (Goldsworthy 1969), Acheta domesticus (Nowosielski \& Patton 1964) and C. morosus (Lohr \& Gade 1983).

Since carbohydrates are used as fuel by insects in the initial flight period (Beenakkers et al. 1985), we believe that hemolymphatic carbohydrates may also be required by reduviids during the first phase of this activity. Preliminary experiments carried 
out in our laboratory with triatomine bugs submitted to flight, showed that a few minutes later the hemolymphatic carbohydrates were undetectable (data not shown).

The insects mobilize the lipids from fat body as diacylglycerols (Beenakkers et al. 1985, Van der Horst et al. 1993). In D. maximus, the hemolymphatic lipids showed a permanent fluctuation , possibly due to their energetic contribution to the vital functions of tissues (Fig. 2). Ward et al. (1982) have suggested that lipids in flight muscle increase probably at the expense of the fat body lipids.

A similar pattern of changes between HDLp levels and hemolymphatic proteins was observed during post-feeding time (Figs 2, 4), reaching both the maximum values at day 20 post-feeding. Moreover, HDLp represented all time evaluated $17-24 \%$ of the hemolymphatic proteins. Our result differs from those found by González et al. (1991) in Triatoma infestans in both, the levels HDLp and the proteins probably due to a different experimental design and the analytical procedure applied for the quantification of HDLp. On the other hand, it has been pointed out that in starved insects, the hemolymphatic proteins play an important role as reserve (Wyatt 1961). D. maximus showed increasing levels of circulating proteins with fasting up to day 20, probably as a consequence of the predominance of the mechanisms of synthesis and transport of absorbed proteins up to deposit organs upon their catabolism (Fig. 4).

Uric acid is the principal nitrogenous excretory product of insects (Wyatt 1961), and more than 90\% of the nitrogen excreted by fed Rhodnius prolixus is represented by this metabolite (Wigglesworth 1931). The levels of uric acid in hemolymph of $D$. maximus increased from day 10 $(0.06 \mathrm{mg} / \mathrm{ml})$ up to $0.16 \mathrm{mg} / \mathrm{ml}$ on day 30 (Fig. 4), in agreement with those reported by Barret and Friend (1966) employing a non-enzymatic method and starving fifth instar of $R$. prolixus.

Since hemolymph volumes decline with time (Barret \& Friend 1966) it is controversial if the uric acid increase observed in D. maximus is due to an increase of proteic catabolism or results merely from a decrease of the hemolymph volume. In case this last assumption were correct, either uric acid would not be produced during starvation or if the uric acid is formed, the amount would be equal to their clearance. Since Wigglesworth (1972) has shown that stored proteins in fat body of $R$. prolixus disappear during starvation, the former suggestion appears more probable.

During the period analyzed, hemolymphatic urea was not detected in D. maximus. For production of urea, arginase has been suggested to be involved in many species of insects (Cochran
1985). Apparently, D. maximus would lack arginase although Friend and Smith (1985) have reported the presence of urea in $R$. prolixus urine 2$3 \mathrm{hr}$ post-feed, pointing to their probable exogen origin.

We conclude that physiological events such as fasting affect the main metabolic processes in these insects. Future research, directed towards the qualitative and quantitative changes of the lipidic components from fat body induced by starvation, may lead to a better physiological and biochemical knowledge of these obligately hematophagous insects and could contribute to understanding the need of one poor nutritional status to begin the flight. In triatomine bugs, flight can take place when food sources are absent or inaccesible or when vectors colonize other geographic areas. Moreover, flight has been pointed out as responsible for the active dispersion of these insects, with implication on their control and on the American trypanosomiasis epidemiology.

\section{ACKNOWLEDGEMENTS}

To Dr Bruno Maggio for critical comments. To Raúl Stariolo from the Servicio Nacional de Chagas (Córdoba) and M Carolina Touz for technical help.

\section{REFERENCES}

Barret FM, Friend WG 1966. Studies on the uric acid concentration in the hemolymph of fifth instar larvae of Rhodnius prolixus (Stal) during growth and metamorphosis. J Insect Physiol 12: 1-7.

Bedford JJ 1977. The carbohydrate levels of insect hemolymph. Comp Biochem Physiol 57 A: 83-86.

Beenakkers AMTh, Van der Horst DJ, Van Marrewijk WJA 1985. Insect lipids and lipoproteins, and their role in physiological processes. Prog Lipid Res 24: 19-67.

Beltran F, Carcavallo RU 1985. Parásitos - Reservorios - Control - Situación Regional, p. 437-442. In RU Carcavallo, JE Rabinovich, RJ Tonn (eds), Factores Biológicos y Ecológicos en la Enfermedad de Chagas, Organización Panamericana de la Salud, Buenos Aires, Argentina.

Bradford M 1976. A rapid and sensitive method for quantitation of proteins utilizing the principle of protein dye binding. Analyt Biochem 72: 248-254.

Canavoso LE, Rubiolo ER 1993. Hemolymphatic components in vectors of Trypanosoma cruzi: Study in several species of the subfamily Triatominae (Hemiptera: Reduviidae). Rev Inst Med Trop São Paulo 35: 123-128.

Canavoso LE, Rubiolo ER 1994. Adipokinetic hormone causes formation of low density lipophorin in the hemolymph of Triatoma infestans. Mem Inst Oswaldo Cruz 89: 233-234.

Canavoso LE, Rubiolo ER 1995. Interconversion of lipophorin particles by adipokinetic hormone in hemolymph of Panstrongylus megistus, Dipetalogaster maximus and Triatoma infestans (Hemi- 
ptera: Reduviidae). Comp Biochem Physiol 112 A: 143-150.

Canavoso LE, Bertello LE, Lederkremer RM, Rubiolo ER 1996. Effect of starvation on lipidic reserves from Triatoma infestans, Dipetalogaster maximus and Panstrongylus megistus (Hemiptera : Reduviidae). Mem Inst Oswaldo Cruz 91 (Suppl.): 129.

Catalá S, Giojalas L, Crocco L 1992. Temperature effect upon blood consuption in Triatoma infestans. Mem Inst Oswaldo Cruz 87: 473-476.

Cochran DG 1985. Nitrogenous excretion, p. 467-506. In GA Kerkut, LI Gilbert (eds), Comprehensive Insect Physiology Biochemistry and Pharmacology, Pergamon Press, Oxford.

Folch J, Lees M, Sloan-Stanley GH 1957. A simple method for the isolation and purification of total lipids from animal tissues. J Biol Chem 226: 497-509.

Friend WG, Smith JJ 1985. Fisiología de los triatominos con especial referencia a la alimentación por sangre, p. 55-72. In RU Carcavallo, JE Rabinovich, RJ Tonn (eds), Factores Biológicos y Ecológicos en la Enfermedad de Chagas, Organización Panamericana de la Salud, Buenos Aires, Argentina.

Frings CS, Dunn RT 1970. A colorimetric method for determination of total serum lipids based on the sulpho-phospho-vanillin reaction. Amer J Pathol 3: 89-91.

Goldsworthy GJ 1969. Hyperglycaemic factors from de corpus cardiacum of Locusta migratoria. J Insect Physiol 15: 2131-2140.

González MS, Soulages JL, Brenner RR 1991. Changes in the hemolymph lipophorin and very high density lipoprotein levels during the fifth nymphal and adult stages of Triatoma infestans. Insect Biochem 21: 679-687.

Gringorten JL, Friend WG 1979. Wing-beat pattern in Rhodnius prolixus Stal (Heteroptera: Reduviidae) during exhaustive flight. Can J Zool 57: 391-395.

Hassid W, Abraham S 1957. Chemical procedures for analysis of polysaccharides, p. 34-37. In SP Colowick, NO Kaplan (eds), Methods in Enzymology, Academic Press, New York.

Jutsum A R, Agarwal HC, Goldsworthy GJ 1975. Starvation and haemolymph lipids in Locusta migratoria $(\mathrm{R} \& \mathrm{~F})$. Acrida 4: 47-52.

Keeley LI 1985. Physiology and biochemistry of the fat body, p. 211-248. In GA Kerkut, LI Gilbert (eds), Comprehensive Insect Physiology, Biochemistry and Pharmacology, Pergamon Press, Oxford.

Lehane MJ, Schofield CJ 1982. Flight initiation in Triatoma infestans (Klug) (Hemiptera: Reduviidae). Bull Entomol Res 72: 497-510.

Lohr P, Gade G 1983. Carbohydrate metabolism in the stick insect, Carausius morosus. J Insect Physiol 29: 287-293.

Mullins DE 1985. Chemistry and physiology of the hemolymph, p. 355-400. In GA Kerkut, LI Gilbert (eds), Comprehensive Insect Physiology, Biochemistry and Pharmacology, Pergamon Press, Oxford.

Nowosielski JW, Patton RL 1964. Daily fluctuation in the blood sugar concentration of the House Cricket,
Gryllus domesticus L. Science 144: 180-181.

Ryckman ER, Ryckman AE 1967. Epizootiology of Trypanosoma cruzi in Southwestern North America. Part X: The Biosystematics of Dipetalogaster maximus in Mexico (Hemiptera, Reduviidae) (Kinetoplastidae,Trypanosomidae). J Med Entomol 4: 180-188.

Schofield CJ 1980. Nutritional status of domestic populations of Triatoma infestans. Trans $R$ Soc Trop Med Hyg 74: 770-778.

Schofield CJ, Lehane MA, McEwen P, Catalá SS, Gorla DE 1992. Dispersive flight by Triatoma infestans under natural climatic conditions in Argentina. Med Vet Entomol 6 : 51-56.

Scott A, Melvin EH 1953. Determination of dextran with anthrone. Analyt Chem 25: 1656-1661.

Sjogren RD, Ryckman RE 1966. Epizootiology of Trypanosoma cruzi in southwestern North America. Part VIII: nocturnal flights of triatoma protracta (Uhler) as indicated by collections at black light traps (Hemiptera: Reduviidae: Triatominae). J Med Ent $3: 81-92$.

Steele JE 1961. Occurrence of a hyperglycaemic factor in the corpus cardiacum of an insect. Nature 192: 680-681.

Szumlewicz AP 1976. Laboratory colonies of Triatominae, biology and population dynamics, $\mathrm{p}$. 63-82. PAHO Scientific Publication No. 318, Washington.

Terra WR, Ferreira C 1994. Insect digestive enzymes: properties, compartmentalization and function. Comp Biochem Physiol 109 B: 1-62.

Van der Horst DJ, Weers PMM, Van Marrewijk WJA 1993. Lipoproteins and lipid transport, p. 1-24. In DW Stanley-Samuelson, DR Nelson (eds), Insect Lipids: Chemistry, Biochemistry and Biology, University Nebraska Press, Lincoln and London.

Voller A, Bidwell DE, Bartlet A 1976. Enzyme immunoassay in diagnostic medicine. Theory and practice. Bull WHO 53: 55-65.

Ward JP, Candy DS, Smith SN 1982. Lipid storage and changes during flight by triatomine bugs (Rhodnius prolixus and Triatoma infestans). J Insect Physiol 28: 527-534.

WHO - World Health Organization 1991. Control de la Enfermedad de Chagas. Bull 811, Geneva, 102 pp.

Wigglesworth VB 1931. The physiology of excretion in a blood-sucking insect, Rhodnius prolixus (Hemiptera:Reduviidae). III. The mechanism of uric acid excretion. J Exp Biol 8: 443-451.

Wigglesworth VB 1972. The circulatory system and associated tissues, p. 411-475. In The Principles of Insect Physiology, Chapman and Hall, London.

Wyatt GR 1961. The biochemistry of insect hemolymph. Annu Rev Entomol 6: 75-102.

Wyatt GR, Pan ML 1978. Insect plasma proteins. Annu Rev Biochem 47: 779-817.

Ziegler R 1991. Changes in lipid and carbohydrate metabolism during starvation in adult Manduca sexta. J Comp Physiol 161 B: 125-131. 